\title{
A Human Ro/SS-A Autoantigen Is the Homologue of Calreticulin and Is Highly Homologous with Onchocercal RAL-1 Antigen and an Aplysia "Memory Molecule"
}

Daniel P. McCauliffe, Eugene Zappi, Tsu-San Lieu, Marek Michalak, * Richard D. Sontheimer, and J. Donald Capra

Departments of Dermatology, Microbiology and Internal Medicine, University of Texas Southwestern Medical Center, Dallas, Texas 75235; and *Cardiovascular Disease Research Group, Departments of Pediatrics and Biochemistry, University of Alberta, Edmonton, Alberta T6G S2S, Canada

\begin{abstract}
The Ro/SS-A (Ro) autoantigens consist of at least four immunologically distinct proteins which are recognized by autoantibodies typically found in sera from patients with primary Sjogren's syndrome and in subsets of patients with lupus erythematosus. We recently isolated a 1.9-kb human cDNA clone which encodes one of these Ro autoantigens. Synthetic oligonucleotides corresponding to the human Ro sequence were used to amplify the homologous gene from a murine $B$ cell cDNA library using the polymerase chain reaction. The mouse cDNA-encoded amino acid sequence was found to be $94 \%$ homologous to the human Ro sequence and is $100 \%$ homologous to murine calreticulin, a high affinity calcium-binding protein which resides in the endoplasmic and sarcoplasmic reticulum. The amino acid sequence of rabbit calreticulin is $92 \%$ homologous to both murine calreticulin and human Ro. Onchocerca volvulus and Drosophila melanogaster also have molecules that are highly homologous to human Ro. In addition, human Ro has a molecular mass, isoelectric point, and significant amino acid sequence similar to the Aplysia californica snail neuronal protein 407 . These homologies suggest that this Ro protein has a very basic cellular function(s) which may in part involve calcium binding. (J. Clin. Invest. 1990. 86:332-335.) Key words: ribonucleoprotein • endoplasmic reticulum • sarcoplasmic reticulum $\bullet$ drosophila $\bullet$ autoimmunity
\end{abstract}

\section{Introduction}

The Ro autoantigens are of clinical interest in that antibodies directed against them are found in the majority of patients with Sjogren's syndrome and several subsets of systemic lupus erythematosus (1-6). There is substantial evidence to support a major role for these antigens and antibodies in the pathogenesis of tissue damage in these clinical disorders (7). Ro was first described as a cytoplasmic antigen by Clark et al. in 1969 (8). Recently it has been demonstrated that there are at least four

Address correspondence and reprint requests to Dr. J. Donald Capra, Department of Microbiology, University of Texas Southwestern Medical Center, 5323 Harry Hines Boulevard, Dallas, TX 75235.

Received for publication 27 February 1990.

J. Clin. Invest.

(C) The American Society for Clinical Investigation, Inc.

0021-9738/90/07/0332/04 \$2.00

Volume 86, July 1990, 332-335 immunologically distinct Ro proteins which react with human Ro antisera, some of which may be localized in the nucleus ( 9 , 10). It had been demonstrated that several of these proteins are complexed with the hY RNAs, yet the cellular functions of these molecules are unknown (11).

We have recently isolated a $1.9-\mathrm{kb}$ cDNA clone that encodes a 46-kD Ro protein that migrates aberrantly at $60 \mathrm{kD}$ by SDS-PAGE (12). This is a single copy gene which has been mapped to the short arm of chromosome 19. Antibodies specific for the protein encoded by this CDNA immunoprecipitate the hY RNAs (12). Southern filter hybridization, even under low stringency, did not reveal other human genes with significant sequence homology to Ro (12). We now present evidence that Ro is highly conserved among species and that it is located in the endoplasmic and sarcoplasmic reticulum where it may bind calcium.

\section{Methods}

Southern filter hybridization. $2 \mu \mathrm{g}$ of DNA from both Saccharomyces cerevisiae and Saccharomyces pombe, $10 \mu \mathrm{g}$ DNA from Drosophila melanogaster, and $10 \mu \mathrm{g}$ of BALB/c mouse DNA was digested with Pst I and Eco RI and then subjected to electrophoresis in a $1 \%$ agarose gel (13). This gel was denatured, dried, prehybridized, and then hybridized with radiolabeled human 1.9-kb Ro cDNA (14). The gel was washed for $40 \mathrm{~min}$ initially at $55^{\circ} \mathrm{C}$ in $0.5 \times \mathrm{SSC}(1 \times \mathrm{SSC}$ is $0.15 \mathrm{M} \mathrm{NaCl}$ and $0.015 \mathrm{M}$ sodium citrate, $\mathrm{pH}$ 7.0), dried, exposed to Kodak X-OMATAR film between intensifying screens overnight, and then developed on a Konica QX-60A film processor. The filter was then rewashed in $0.4 \mathrm{X} \mathrm{SSC}$ at $60^{\circ} \mathrm{C}$ for $30 \mathrm{~min}$ and exposed to film.

Polymerase chain reaction. Synthetic oligonucleotides 18-24 nucleotides long were made corresponding to both strands of the cDNA at $\sim 300$-bp overlapping intervals. The oligonucleotides were phosphorylated (13) and used in the polymerase chain reaction (PCR) ${ }^{1}$ with the DNA amplification system (Perkin-Elmer Corp., Norwalk, CT) using 5 ng of mouse cDNA prepared from mouse B cell (BCL1) RNA with the cDNA synthesis system (Bethesda Research Laboratories, Gaithersburg, MD). The resulting PCR amplification products were directly ligated into Sma I-digested M13mp19 plasmid (Boerhinger Mannheim Biochemicals, Indianapolis, IN) after two ammonium acetate and one sodium acetate/ethanol precipitations $(15,16)$. Single strand DNA was generated (16) and sequenced by the Sanger dideoxy method with $\alpha^{-35}$ S-dATP and modified T7 DNA polymerase (Sequenase) according to manufacturer's recommendations (United States Biochemical Corp., Cleveland, $\mathrm{OH}$ ).

Genomic library screening. Sau IIIA partially digested D. melanogaster genomic DNA was ligated into the Bam HI sites of Lambda

1. Abbreviation used in this paper: PCR, polymerase chain reaction. 
phage PEMBL (Stratagene Inc., La Jolla, CA). (This genomic library was obtained from Dr. Stephen Wasserman, Dept. of Biochemistry, University of Texas, Southwestern Medical Center, Dallas, TX.) The filter lift and hybridization technique (13) utilizing radiolabeled human 1.9-kb Ro cDNA allowed the isolation of several genomic clones. One of these clones contained a 4-kb insert that hybridized to fragments from the 5'-and 3'-most portions of the Ro cDNA. This 4-kb fragment was subcloned into pTZ 18U plasmid vector (United States Biochemical Corp.). Restriction enzyme digestion of the 4-kb fragment produced a $1.6-\mathrm{kb}$ Bam $\mathrm{HI}$ fragment and a $1.3-\mathrm{kb}$ Acc I fragment, which were ligated into $\mathrm{M} 13 \mathrm{mp} 19$ to generate single stranded DNA for sequencing (16).

\section{Results}

The previously isolated human 1.9-kb Ro cDNA (12) was used for Southern filter hybridization analysis of mouse, drosophila, and yeast genomic DNA and revealed that mice and drosophila have a single highly homologous gene whereas yeast do not (data not shown). Using synthetic oligonucleotides corresponding to the human Ro cDNA sequence and mouse B cell cDNA as a template, a series of overlapping PCRs were performed to obtain DNA fragments of the mouse Ro homologue for sequencing. DNA sequencing revealed that the mouse nucleic acid sequence is $87 \%$ homologous to that of the human Ro gene. The mouse cDNA-encoded protein sequence is $94 \%$ homologous to the human protein sequence (Fig. 1) and is $100 \%$ homologous with the protein encoded by the recently isolated murine calreticulin cDNA clone (17). The amino acid sequence of this Ro protein and murine calreticulin are both 92\% homologous with rabbit calreticulin (18) (Fig. 1). Calreticulin is a high affinity calcium-binding protein located in the endoplasmic and sarcoplasmic reticulum (17-19).

A drosophila genomic clone which hybridized to radiolabeled human 1.9-kb Ro cDNA was isolated and partially sequenced. The DNA sequence confirms that drosophila have a gene which encodes a protein highly homologous to human Ro (the partially deduced amino acid sequence is $82 \%$ homologous) (Fig. 1). The human Ro sequence is also 63\% homologous to the partially sequenced Onchocerca volvulus RAL-1 molecule (Fig. 1) (20). Many of the drosophila residues that differ from the human Ro sequence are identical to the onchocercal residues, indicating phylogenetic conservation of this protein.

Human Ro as well as murine and rabbit calreticulin have similar molecular masses and amino terminal amino acid sequences to the Aplysia californica neuronal "memory molecule" protein 407 (p407) (21), rat fibroblast protein 425 (p425) (21), and murine melanoma protein B50 (22) (Table I). The measured isoelectric point of both human Ro and aplysia p407 is $4.7(23,24)$.

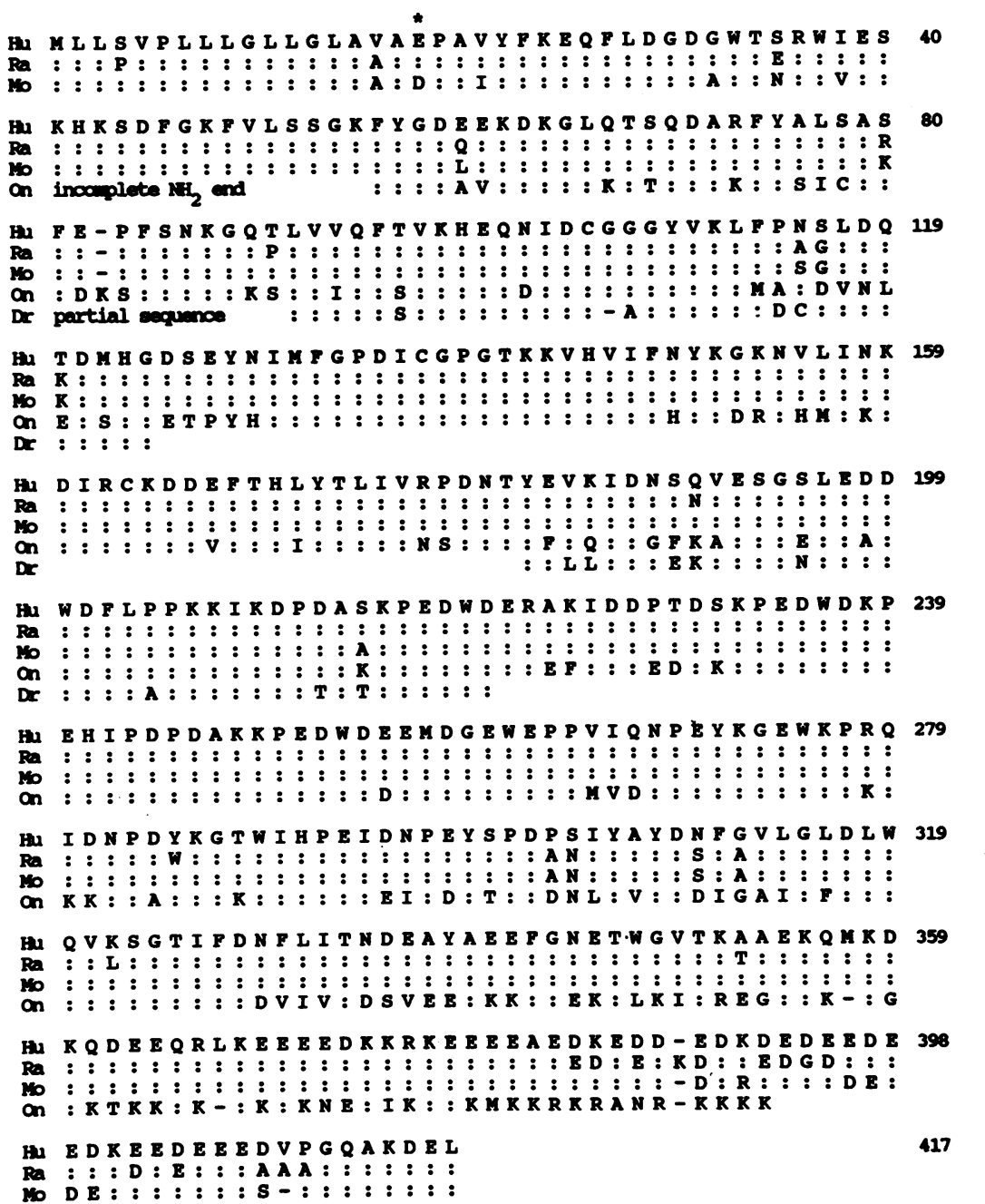

\section{0}

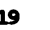
40

(1)


Table I. Human Ro Amino-terminal Sequence and Molecular Mass Comparisons with Other Proteins

\begin{tabular}{|c|c|c|c|}
\hline Protein & Amino-terminal sequence & $\begin{array}{l}\text { Molecular mass } \\
\text { (SDS-PAGE) }\end{array}$ & Reference \\
\hline & & $k D$ & \\
\hline Human Ro & E PAVYFKEQF L D G DWTS & 60 & 12 \\
\hline Murine calreticulin & $\mathrm{D}:: \mathrm{I}::::::::: \mathrm{A}:: \mathrm{N}$ & 55 & 17 \\
\hline Rabbit calreticulin & : : : : : : : : : : : : : : : : E & 55 & 18 \\
\hline Murine B50 & ? ?: I : : : : : : :N :NA?? & 50 & 22 \\
\hline Aplysia p407 & $?: \mathrm{T}::::: \mathrm{E}: \mathrm{G}: \mathrm{D} ? \mathrm{AE} ?$ & 52 & 21 \\
\hline Rat p425 & 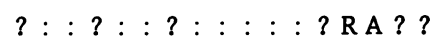 & 52 & 21 \\
\hline
\end{tabular}

(:), same as Ro amino acid; (?), undetermined.

\section{Discussion}

These data suggest that this human Ro molecule is the homologue of murine and rabbit calreticulin and that drosophila onchocerca, and aplysia all have a homologous molecule. This protein is apparently sequestered in the endoplasmic reticulum and has a basic function(s) in cellular metabolism which in part involves the binding of calcium. Previous Southern hybridization analysis of human genomic DNA with radiolabeled Ro cDNA failed to reveal other cross-hybridizing genes (12). Under similar conditions the cDNA hybridized to a single species of mouse genomic DNA by Southern blot analysis. These data and the Ro sequence similarity with murine and rabbit calreticulin indicate that Ro is human calreticulin. Preliminary studies indicate that this human Ro protein binds calcium (unpublished observation). Immunofluorescence staining with anti-calreticulin sera reveals a cytoplasmic pattern of fluorescence (19) identical to the pattern previously demonstrated with human anti-Ro sera (25). Additionally, goat anti-calreticulin antibodies bind human Ro by immunoblot analysis, and human anti-Ro antibodies produce a precipitin reaction with rabbit calreticulin by immunoelectrophoresis (unpublished observations).

Patients infected with $O$. volvulus, a filarial nematode that causes river blindness, sclerosing lymphadenitis, as well as generalized and localized forms of dermatologic disease in humans living in parts of Africa and Central America, have antibodies directed against onchocercal RAL-1 antigen (20, 26). The sequence similarity between RAL-1 and Ro raises the possibility that a foreign Ro protein homologue might trigger an autoimmune response directed at self-Ro.

The homologies between Ro, RAL-1, and the drosophila Ro homologue are striking considering that mammals diverged phylogenetically $\sim 75$ million years ago and drosophila and onchocerca diverged over 250 million years ago (27). Fig. 1 shows that there are multiple areas where the amino acid sequences are identical between species. These include a sequence predicted to form highly structured antiparallel beta strands (residues 130-148) and a proline-rich sequence (residues 232-254). The areas that are most conserved might well be areas of greatest structural and functional importance. The area of least homology, particularly in the onchocercal protein, is at the carboxy end of the molecule. The carboxy terminus of the onchocercal protein is highly charged like the other proteins, although it is positively rather than negatively charged.

The isoelectric point, molecular mass, and amino acid se- quence similarity between human Ro and aplysia p407 suggests that p407 may be the California marine snail homologue of this human Ro molecule $(23,24)$. The amino-terminal sequence of rat $\mathrm{p} 425$, the putative homologue of aplysia $\mathrm{p} 407$, has even greater homology with Ro. Staphylococcus aureus $\mathrm{V}-8$ protease digestion of $\mathrm{p} 407, \mathrm{p} 425$, and Ro each produce a major fragment $\sim 20 \mathrm{kD}$ in size and each fragment has the amino-terminal amino acid sequence shown in Table I. $(12,21)$.

These data indicate that this human Ro molecule, which is most likely human calreticulin, is highly conserved across species and probably has a very basic cellular function(s) which in part involves calcium binding. Several different laboratories working independently on seemingly unrelated areas have encountered this highly conserved protein whose functions are of interest to scientists studying rather diverse biological processes.

\section{Acknowledgments}

We are grateful to Jeff Wilson for his excellent technical assistance and to Dr. Barbara Fishel and Dr. Stephen Wasserman for providing genomic DNA utilized in these studies.

Dr. McCauliffe is the recipient of a Dermatology Foundation Career Development Award, Dr. Sontheimer is the recipient of a National Institutes of Health (NIH) Research Career Development Award and, Dr. Michalak is a Scholar of the Alberta Heritage Foundation for Medical Research. This work was supported in part by grants from the NIH and the Medical Research Council of Canada.

\section{References}

1. Martinez-Lavin, M., J. H. Vaughan, and E. M. Tan. 1979. Autoantibodies and the spectrum of Sjogren's syndrome. Ann. Intern. Med. 91:185-190.

2. Sontheimer, R. D., P. J. Maddison, M. Reichlin, R. E. Jordon, P Stastny, and J. N. Gilliam. 1982. Serologic and HLA associations in subacute cutaneous lupus erythematosus, a clinical subset of lupus erythematosus. Ann. Intern. Med. 97:664-671.

3. Maddison, P. J., T. T. Provost, and M. Reichlin. 1981. ANA negative systemic lupus erythematosus: serologic analysis. Medicine (Baltimore). 60:87-94.

4. Kephart, D., A. F. Hood, and T. T. Provost. 1981. Neonatal lupus: serologic findings. J. Invest. Dermatol. 77:331-333.

5. Provost, T. T., F. C. Arnett, and M. Reichlin. 1983. Homozygous $\mathrm{C} 2$ deficiency, lupus erythematosus and anti-Ro(SSA) antibodies. Arthritis Rheum. 26:1279-1282.

6. Meyer, O., G. Hauptmann, G. Tuppeiner, H. D. Ochs, and F. 
Mascart-Lemone. 1985. Genetic deficiency of C4, C2 or C1q and lupus syndromes: association with anti-Ro(SS-A) antibodies. Clin. Exp. Immunol. 62:678-684.

7. McCauliffe, D. P., F. A. Lux, T.-S. Lieu, I. Sanz, J. Hanke, M. M. Newkirk, M. J. Siciliano, R. D. Sontheimer, and J. D. Capra. 1989. Ro/SS-A and the pathogenic significance of its antibodies. Journal of Autoimmunity. 2:375-381.

8. Clark, G., M. Reichlin, and T. B. Tomasi. 1969. Characterization of a soluble cytoplasmic antigen reactive with sera from patients with systemic lupus erythematosus. J. Immunol. 102:117-122.

9. Rader, M. D., C. O'Brien, Y. Liu, J. B. Harley, and M. Reichlin. 1989. The heterogeneity of the Ro/SS-A antigen. Different molecular forms in lymphocytes and red blood cells. J. Clin. Invest. 83:12931298.

10. Harmon, C. E., J. S. Deng, C. L. Peebles, and E. M. Tan. 1984. The importance of tissue substrate in the SS-A/Ro antigen-antibody system. Arthritis Rheum. 27:166-173.

11. Ben-Chetrit, E., E. K. Chan, K. F. Sullivan, and E. M. Tan. 1988. A 52-kD protein is a novel component of the SS-A/Ro antigenic particle. J. Exp. Med. 167:1560-1571.

12. McCauliffe, D. P., F. Lux, T.-S. Lieu, I. Sanz, J. Hanke, M. M. Newkirk, L. L. Bachinski, Y. Itoh, M. J. Siciliano, M. Reichlin, R. D. Sontheimer, and J. D. Capra. 1990. Molecular cloning, expression and chromosome 19 localization of a human Ro/SS-A autoantigen. J. Clin. Invest. 85:1379-1391.

13. Ausubel, F. M. 1987. Current Protocols in Molecular Biology. John Wiley and Sons, Inc., New York.

14. Purrello, M., and I. Balazs. 1983. Direct hybridization of labeled DNA to DNA in agarose gels. Anal. Biochem. 128:393-397.

15. Maniatas, T., E. Fritsch, and J. Sambrook. 1982. Molecular Cloning: A Laboratory Manual. Cold Spring Harbor Laboratory, Cold Spring Harbor, NY.

16. Yanisch-Perron, C., J. Vieira, and J. Messing. 1985. Improved M13mp phage cloning vectors and host strains: nucleotide sequences of the M13mp18 and pUC19 vectors. Gene (Amst.) 33:103-119.

17. Smith, M. J., and G. L. Koch. 1989. Multiple zones in the sequence of calreticulin (CRP55, calregulin, HACBP), a major calcium binding ER/SR protein. EMBO (Eur. Mol. Biol. Organ.) J. 8:3581-3586.
18. Fliegel, L., K. Burns, D. H. MacLennan, R. A. Reithmeier, and M. Michalak. 1989. Molecular cloning of the high affinity calciumbinding protein (calreticulin) of skeletal muscle sarcoplasmic reticulum. J. Biol. Chem. 264:21522-21528.

19. Fliegel, L., K. Burns, M. Opas, and M. Michalak. 1989. The high-affinity calcium binding protein of sarcoplasmic reticulum: tissue distribution, and homology with calregulin. Biochim. Biophys. Acta. 982:1-8.

20. Unnasch, T. R., M. Y. Gallin, P. T. Soboslay, K. D. Erttmann, and B. M. Greene. 1988. Isolation and characterization of expression cDNA clones encoding antigens of Onchocerca volvulus infective larvae. J. Clin. Invest. 82:262-269.

21. Kennedy, T. E., M. A. Gawinowicz, A. Barzilai, E. R. Kandel, and J. D. Sweatt. 1988. Sequencing of proteins from two-dimensional gels by using in situ digestion and transfer of peptides to polyvinylidene difluoride membranes: application to proteins associated with sensitization in Aplysia. Proc. Natl. Acad. Sci. USA. 85:7008-7012.

22. Hearing, V. J., J. J. Marchalonis, and D. M. Gersten. 1986. Characterization of immunologically significant unique B16 melanoma proteins produced in vivo and in vitro. JNCI (J. Natl. Cancer Inst.). 77:763-766.

23. Lieu, T.-S., M. Jiang, J. C. Steigerwald, and E. M. Tan. 1984. Identification of the SS-A/Ro intracellular antigen with autoimmune sera. J. Immunol. Methods. 71:217-228.

24. Castellucci, V. F., T. E. Kennedy, E. R. Kandel, and P. Goelet. 1988. A quantitative analysis of $2-D$ gels identifies proteins in which labeling is increased following long-term sensitization in Aplysia. Neuron. 1:321-328.

25. Hendrick, J. P., S. L. Wolin, J. Rinke, M. R. Lerner, and J. A. Steitz. 1981. Ro small cytoplasmic ribonucleoproteins are a subclass of La ribonucleoproteins: further characterization of the Ro and La small ribonucleoproteins from uninfected cells. Mol. Cell. Biol. 1:11381149.

26. Connor, D. H., G. H. George, and D. W. Gibson. 1985. Pathologic changes of human onchocerciasis: implications for future research. Rev. Infect. Dis. 7:809-819.

27. Weisz, P. B. 1973. The Science of Zoology. McGraw-Hill Inc., New York. 311-340. 